Brit. J. industr. Med., 1955, 12, 50.

\title{
INJURY TO THE RESPIRATORY TRACT BY ISOCYANATES USED IN MAKING LACQUERS
}

\author{
BY
}

ÅKE SWENSSON, CARL-ERIC HOLMQUIST, and KARL-DAVID LUNDGREN

From the Division of Occupational Medicine, Karolinska Hospital, Stockholm, and the Department of Occupational Hygiene, State Institute of Public Health, Tomteboda, Sweden

(RECEIVED FOR PUBLICATION AUGUST 9, 1954)

Bayer, Rinke, Siefken, Orthner, and Schild in 1937 and 1942 demonstrated the possibility of producing high molecular compounds with extraordinary chemical and physical properties by means of a so-called diisocyanate-polyaddition procedure. The basic reaction, leading to low-molecular products, had been known for about 100 years. Bayer and his colleagues were able to show, however, that the reaction between a diisocyanate, e.g., 1,6-hexanediisocyanate and a divalent alcohol, e.g., 1,4-butylene-glycol, led to the formation of a linear polymer, a polyurethane that could be spun. This product was given the name " perlon U". If the reaction takes place between a diisocyanate and compounds with more than two hydroxyl groups, e.g., alkydresins with free OH-groups, one obtains high-molecular compounds with a network structure. Through the variation of the polyester types (the alkydresins) it is possible so to change the properties of the final product that one gets hard and brittle products of alkyds built upon glycerol and phthalic acid as well as soft and elastic products of alkyds built upon aliphatic carbonic acids and glycols. The di- or tri-isocyanates have been given the trade name "desmodur" with varying designations according to particular type, while the polyesters are called " desmophen". Of over 100 diisocyanates, only about 15 can be produced technically. Of interest are the " desmodur" types T, TH, and THN. "Desmodur T" consists of a mixture of $60 \% \mathrm{~m}$-tolylene diisocyanate and $40 \%$ p-tolylene diisocyanate. It is a fluid with low viscosity with a flash point of $+132^{\circ} \mathrm{C}$. and melting points of +5 to $+7^{\circ} \mathrm{C}$. At the time of the cases described in this paper probably only "desmodur TH" was used in Sweden. This is a compound of 3 mol. " desmodur
$\mathrm{T}$ " and $1 \mathrm{~mol}$. hexane triol (Bayer, 1947). It consists of an almost odourless resinous mass which appears commercially dissolved in a solvent such as ethyl acetate or in a mixture of ethyl acetate and toluene. It contains about $15 \%$ of the primary substance "desmodur T" (Reinl, 1953). More recently, Farbenfabrik Bayer in Leverkusen has also produced "desmodur THN", whose composition is not known to us. In this product, too, however, one may probably assume that there are traces of " desmodur T". The isocyanates are chemically extraordinarily reactive and combine easily with primary $\mathbf{N H}_{2}$-groups, water, alcohols, carbonic acids, phenols and, in general, with compounds having a reactive hydrogen atom which may theoretically be replaced with an alkali metal.

\section{Use of Desmophen and Desmodur}

The two components " desmophen" and " desmodur" in suitable solvents are mixed in stoicheiometric proportions just before use. After half an hour to an hour the mixture may be applied by means of brushing, dipping, or spraying. The reaction between the components takes place at ordinary temperatures, which makes the lacquer a suitable material for corrosion-resisting and chemically stable protective coatings for metal, wood, and concrete. The electric resistance of the lacquer is high, which renders it useful as an insulating covering.

\section{Physiological Properties}

There are in the literature extremely few reports of the toxicity of the compounds mentioned. The final product and the "desmophen" types are considered to be physiologically inactive. 
Diisocyanates with relatively high vapour pressures such as "desmodur $\mathrm{T}$ " are physiologically highly active, while TH is said to be without vapour pressure and without toxic effect (Bayer 1947; Hebermehl, 1948). As far as we have been able to ascertain, however, no study on the toxicity of this compound has been published. With 2,4-tolylene diisocyanate, which forms the main component in " desmodur T", Gross and Hellrung (1941) have carried out unpublished experiments (Reinl, 1953) with mice, rabbits, and cats. When it was administered subcutaneously to mice the animals tolerated more than $10 \mathrm{~g} . / \mathrm{kg}$. body weight without reaction. According to information we have received from Du Pont Rubber Laboratory, U.S.A., tests of 2,4-tolylene diisocyanate (TDI), which corresponds to "desmodur $\mathrm{T}$ ", have shown the minimum lethal dose of this substance for white mice to be 4.8 to $6.0 \mathrm{~g}$. $/ \mathrm{kg}$. body weight. A certain cumulative effect has also been demonstrated (Neal, 1953). Fuchs and Valade (1951) state that on subcutaneous administration of an oil-solution of "desmodur $\mathrm{T}$ ", guinea-pigs tolerate more than $500 \mathrm{mg}$. $/ \mathrm{kg}$. body weight without reaction.

Gross and Hellrung (according to Reinl, 1953) found that undiluted "desmodur $T$ ", applied direct to the ears of rabbits, could cause reddening, swelling, and necrosis, which healed with formation of a crust. The degree of the injury depended upon the duration of the exposure. One drop of "desmodur $T "$ in the conjunctival sacs of rabbits resulted in an immediate lacrimal flow and pronounced irritation, a marked inflammatory reaction.

Gross and Hellrung also carried out inhalation experiments with four-hour exposures of rabbits and cats. The concentrations used are not given. The animals reacted with pronounced irritation of the mucous membranes of the eye and nose. Higher concentrations resulted in irritation further down in the respiratory passages. A number of animals died after the experiment, and necropsy showed oedema of the lungs, pneumonia, bronchitis, and tracheitis. In one or two cases the kidney was damaged.

Fuchs and Valade (1951) performed inhalation experiments with monkeys, rabbits, and guineapigs. The inhaled air contained 1 to $2 \mathrm{~g}$. " desmodur $T^{\prime \prime} / \mathrm{m}^{3}$. The rabbits and guinea-pigs reacted with sneezing, polypnea, and lacrimation. All the symptoms rapidly disappeared when the exposure was discontinued and all the animals survived.

\section{Effects of Industrial Exposure}

There are very few published data of injuries after industrial exposure to these substances. The first publication we have been able to find is an article by Fuchs and Valade (1951), who examined the workers in a factory for the production of a plastic mass with vinyl resins and "desmodur $T$ " as primary materials. They state that during a first period, varying between eight days and two months, the workers had no serious trouble but merely complained of a slight irritation of the mucous membrane of the conjunctiva, slight lacrimation, and prickling sensations in the throat. After this appears progressive bronchial irritation with an irritating dry cough and dyspnoea, which may be at its worst during the night and prevent sleep. Asthmatic attacks may also occur. The symptoms recede quite rapidly when the exposure is discontinued, only to return in many cases in the form of an acute attack on renewed, even very short and slight, exposure.

Holmquist, Lundgren, and Swensson (1953) made the same observations as Fuchs and Valade. The findings were further confirmed by Reinl (1953).

At the Department of Occupational Medicine we have so far had occasion to examine and follow up 15 patients with more or less severe symptoms from the respiratory passages as a result of exposure to "desmodur". In all these cases the symptoms manifested receded in a short time after cessation of exposure. The picture and course of the affection are fairly monotonous, and the different cases show only minor variations, so we give only illustrative, typical cases.

\section{Case Histories}

Case 1.-B. G. T. N.-n., born in 1912, did not as a rule easily catch cold. He had never had any pulmonary affection or asthma nor had he any family history of allergy.

About three months before examination he began spray-painting with polyisocyanate lacquer. He worked in a room with a ventilated spray-painting booth, but this was not sufficient to control the vapours from spraying. After two months he began to have trouble from the respiratory tract, with an irritating cough and dyspnoea but no sputum. He was better during the holidays. He returned to work again for one week and had increasing shortness of breath, pressure on the chest, and coughing without sputum. He then attended the out-patient department on July 29, 1953.

On examination it was found that he had no dyspnoea when resting but slight dyspnoea when walking, inconsiderable pharyngitis, a normal heart, and a blood pressure of $145 / 100 \mathrm{~mm}$. $\mathrm{Hg}$. Rhonchi and rales were heard all over the chest.

The sedimentation rate was $3 \mathrm{~mm}$., Hb $92 \%$, white blood corpuscles 4,100 per c.mm.

A radiograph of the lungs on July 29 showed no 
parenchymal or pleural shadows and the hilar shadows were normal.

Spirometry on August 6 gave a total capacity of 7.94 litres, a vital capacity of 6.67 litres, and a residual quotient of $18 \%$. These are normal spirometric values.

Separate skin tests with the different constituents of the lacquer were negative.

In this case we have the picture of asthmatic bronchitis in a man who never previously had any asthmatic trouble or more pronounced symptoms of any kind from the respiratory tract. We have no evidence that an infection of the upper respiratory tract played any role. He showed impaired lung function of the kind met with in asthma, which recedes when exposure is discontinued. What remains for a longer period is a subjectively increased sensitivity to the odour of solvents.

Case 2.-B. S. D.-t. was born in 1914 and had no family history of allergic affections or of asthma. Hitherto he had always been healthy, and had had no respiratory ailments.

In 1951 the patient studied polyisocyanate plastic painting in Germany where he worked in an old cellar. During the first period he had only slight symptoms of irritation from the respiratory tract. He then caught cold and had severe bronchial symptoms with pronounced dyspnoea, whistling in the chest when breathing, and fits of coughing but no expectoration. He has since been sensitive to "desmodur" and has reacted with asthmatic symptoms at every exposure, perhaps a couple of hundred times. He is now extremely sensitive and even had a reaction from being in the same room as another person who had been present for a time while plastic spray-painting was going on. He is able to state, moreover, that it is the "desmodur" component he is sensitive to for he comes into contact with other solvents without any symptoms being caused.

Each separate attack recedes, as a rule, after 10 to 12 hours, and he then feels fit again. He has never had similar attacks from any other cause.

He attended the out-patient department on May 29, 1953.

On examination he had dyspnoea when resting, noticeably increased during conversation or while walking. The throat was normal. Expiration was prolonged, and rhonchi were heard diffusely over both lungs. The heart was normal. Blood pressure was $150 / 90 \mathrm{~mm}$. $\mathrm{Hg}$.

The sedimentation rate was $3 \mathrm{~mm}$., $\mathrm{Hb} 100 \%$, white blood corpuscles 6,700 (5.5\% eosinophils).

Spirometry gave a total capacity of $7 \cdot 11$ litres, a vital capacity of 3.59 litres, and a residual quotient of $50 \%$. Spirometric values were as in pronounced emphysema, namely a large total capacity, small vital capacity and complementary air, and a large residual capacity in relation to the total capacity. He was given $10 \mu \mathrm{g}$. adrenalin intravenously which resulted in immediate but transient subjective relief. In response to theophyllamine glucose the symptoms rapidly dis- appeared, and the patient has since been free of symptoms.

In this case the asthmatic reaction seems to have appeared for the first time concurrently with an infection of the upper respiratory passages, and after this the hypersensitivity has become permanent so that the patient has reacted with asthmatic attacks on renewed exposure.

The possible importance of an infection for the appearance of the symptoms must also be considered in the following case.

Case 3.-E. O. W.-m., born in 1914, was repeatedly treated for an ulcer and had an obstinate cold in the spring of 1953.

A radiograph of the nasal sinuses on February 2, 1953, showed swelling of the basal mucous membrane in the large left frontal sinus while the right sinus appeared on the whole normal. Shadows were seen in the ethmoidal cells of both sides, pronounced swelling of the mucous membrane in both maxillary sinuses, and swelling of the left nasal cavity. The $x$-ray picture was otherwise normal. The patient had no family history of asthma or other allergic complaints. He has been a painter since leaving school.

Since the middle of March he had been engaged in spray-painting with plastic lacquer, with a short period of brush-painting. He stated that when spraying he wore an air-line respirator but for certain jobs was unable to wear a mask. After the first day's spraying he had a severe cough in the night so that he had to sit up in bed for an hour. On succeeding days he felt pressure on the chest while working, and thought he was not getting any air. He had to go out in the fresh air every now and then to breathe and felt relief on these occasions. He had a rather severe irritating cough but no sputum. The cough was especially trying at night. He found it difficult to remain lying down and often had to sit up for three or four hours on account of cough. He stopped work after two weeks' spray-painting and symptoms have since then slowly receded. He still feels tired. The cough now appears chiefly on physical effort, but dyspnoea is not troublesome.

He attended the out-patient department on April 23, 1953.

On examination he appeared healthy with no dyspnoea, a normal pharynx and heart. The blood pressure was $150 / 70 \mathrm{~mm}$. $\mathrm{Hg}$ and the lungs were normal.

The sedimentation rate was $5 \mathrm{~mm}$., $\mathrm{Hb} 93 \%$, white blood count 7,000 (differential count normal, eosinophils $2 \%$ ). A radiograph of the lungs was normal.

A radiograph of the nasal sinuses showed as before a slight swelling of the mucous membrane in the left frontal sinus. The ethmoidal cell regions on both sides were rather denser than before and the shadow in the maxillary sinuses had somewhat increased. No levels were visible. A test puncture of the maxillary sinus bilaterally yielded nothing.

Spirometry gave a total capacity of 8.36 litres, a vital capacity of 5.50 litres, residual quotient $34 \%$, and indicated slight emphysema. 
Nothing pathological was seen on an E.C.G. at rest and an ordinary reaction was obtained after work.

A feature common to all the cases is a family and personal history without asthma and bronchial symptoms, and that the current symptoms had first appeared after exposure for a shorter or longer period without severe symptoms. In some cases an infection of the upper respiratory passages has acted as a trigger, but this is by no means always the case. On discontinuance of the exposure the symptoms gradually recede, but increased sensitivity appears to remain so that on renewed exposure the symptoms return at once.

\section{Prophylaxis}

Owing to the irritating effect of " desmodur $T$ ", upon the mucous membrane it is important to take adequate precautions. This is the more necessary in view of the sensitizing capacity of the substance.

In spray-painting in a spray-booth the facevelocity of the air commonly used with ordinary paints should probably be considerably increased. Preferably, an air-line respirator should be used. In brush-painting out of doors there is probably sufficient ventilation, but in indoor work respiratory protection is desirable, at least in bigger jobs and on prolonged work.

In connexion with the cases of poisoning described we did not carry out any air analyses to determine the content of "desmodur" in the atmosphere. It is, however, a fairly simple matter to determine the number of reactive NCO-groups by coupling to a secondary amine in a suitable solvent, e.g., chlorobenzene. Unconverted amine may thereafter be back-titrated with hydrochloric acid (Bayer, 1947). The value of air analyses appears to us to be limited in view of the sensitizing capacity of the isocyanates.
It is important that all who work with " desmodur" compounds should be informed of the risks entailed in the work and how protection may be achieved.

\section{Therapy}

The irritation in the conjunctivae and respiratory passages is slight and disappears rapidly. As a rule, no treatment is required ; only in exceptional cases may symptomatic treatment be in order. The rational treatment is to reduce the exposure with adequate technical measures. This will also reduce the risk of sensitizing those exposed. The asthmatic attack, when sensitization has occurred, calls for ordinary symptomatic treatment. When the acute reaction has subsided the patient should be protected from renewed exposure.

\section{Summary}

A number of isocyanates which are used for the production of certain lacquers may cause symptoms of irritation from the mucous membranes of the eye and the respiratory passages. In addition to this, sensitization may occur whereby renewed exposure will give rise to regular asthmatic attacks.

Previous investigations are reviewed and typical cases are described. Technical protective measures are discussed.

\section{REFERENCES}

Bayer, O. (1947). Angew. Chem. A, 59, 257. Rinke, H., Siefken, W., Orthner, L., and Schild (1937 and 1942) Deutsches Reich Patentschrift, 728981.

W., Bayer, O., Petersen, S., and Spielberger, G. (1953).

Bunge, W., Bayer, O., Petersen, S., and

Fuchs, S., and Valade, P. (1951). Arch. Mal. prof., 12, 191.

Fuchs, S., and Valade, P. (1951). Arch. Mal. prof

Hebermehl, R. (1948). Farb. Lack., Anstrichst., 2. 123. Svenska LäkT., 50, 183 .

Neal, A. M. (1953). Personal communication to C.-E. Holmquist. Reini, W. (1953). Zbl. ArbMed. ArbSchutz., 3, 103. 